\title{
OVERVIEW OF STATES' USE OF TELEHEALTH FOR THE DELIVERY OF EARLY INTERVENTION (IDEA PART C) SERVICES
}

\author{
JANA CASON, DHS, OTR/L'; DIANE BEHL, M.ED.²; \\ SHARON RINGWALT, PHD, CCC-SLP3
}

\author{
1SPALDing UNIVERSITY, LOUISVILLE, KENTUCKY; ${ }^{2}$ NATIONAL CENTER FOR HEARING ASSESSMENT AND \\ MANAGEMENT (NCHAM), UTAH STATE UNIVERSITY, LOGAN, UTAH; \\ ${ }^{3}$ NATIONAL EARlY CHILDHOOD TECHNICAL ASSISTANCE CENTER (NECTAC) AND MID-SOUTH REGIONAL \\ Resource Center (MSRRC), Chapel Hill, NORTH CAROlinA
}

\section{ABSTRACT}

Background: Early intervention (El) services are designed to promote the development of skills and enhance the quality of life of infants and toddlers who have been identified as having a disability or developmental delay, enhance capacity of families to care for their child with special needs, reduce future educational costs, and promote independent living (NECTAC, 2011). El services are regulated by Part C of the Individuals with Disabilities Education Improvement Act (IDEA); however, personnel shortages, particularly in rural areas, limit access for children who qualify. Telehealth is an emerging delivery model demonstrating potential to deliver El services effectively and efficiently, thereby improving access and ameliorating the impact of provider shortages in underserved areas. The use of a telehealth delivery model facilitates inter-disciplinary collaboration, coordinated care, and consultation with specialists not available within a local community. Method: A survey sent by the National Early Childhood Technical Assistance Center (NECTAC) to IDEA Part C coordinators assessed their utilization of telehealth within states' IDEA Part C programs. Reimbursement for provider type and services and barriers to implement a telehealth service delivery model were identified.

Results: Representatives from 26 states and one jurisdiction responded to the NECTAC telehealth survey. Of these, $30 \%(n=9)$ indicated that they are either currently using telehealth as an adjunct service delivery model $(n=6)$ or plan to incorporate telehealth within the next $1-2$ years $(n=3)$. Identified telehealth providers included developmental specialists, teachers of the Deaf/Hard of Hearing $(\mathrm{DHH})$, speech-language pathologists, occupational therapists, physical therapists, behavior specialists, audiologists, and interpreters. Reimbursement was variable and included use of IDEA Part C funding, Medicaid, and private insurance. Expressed barriers and concerns for the implementation of telehealth as a delivery model within Part C programming included security issues $(40 \% ; n=11)$; privacy issues $(44 \%$; $n=12)$; concerns about quality of services delivered via telehealth (40\%; $n=11)$; and lack of evidence to support the effectiveness of a telehealth service delivery model within IDEA Part $C$ programming $(3 \% ; n=1)$. Reimbursement policy and billing processes and technology infrastructure were also identified as barriers impacting the implementation of telehealth programming.

Conclusions: Provider shortages impact the quantity and quality of services available for children with disabilities and developmental delay, particularly in rural areas. While many states are incorporating telehealth within their Early Intervention (IDEA Part C) services in order to improve access and overcome personnel shortages, barriers persist. Policy development, education of stakeholders, research, utilization of secure and private delivery platforms, and advocacy may facilitate more widespread adoption of telehealth within IDEA Part C programs across the country.

Keywords: Telehealth, tele-intervention, telerehabilitation, Individuals with Disabilities Education Improvement Act (IDEA), early intervention services

\section{INTRODUCTION}

In 1986, Congress encouraged the provision of early intervention services by providing federal funding through Part $\mathrm{C}$ of the Individuals with Disabilities Education Improvement Act (IDEA). Early Intervention (EI) services target children birth through two years of age who meet state-specific criteria for having or being at risk of developing a developmental delay. These services are designed to enhance acquisition of developmental milestones, empower families to meet the needs of their child with special needs, reduce future educational costs by minimizing the need for special education services, and promote independent living, thereby decreasing the likelihood of institutionalization (IDEA, 2004; NECTAC, 2011; 2012a). 
INCREASING DEMAND FOR EARLY

INTERVENTION (IDEA PART C) SERVICES

Higher prevalence of developmental disabilities, cerebral palsy, child abuse, homelessness, prematurity, and pre-natal substance exposure--all associated with potential delays in motor, cognitive, communication, social-emotional, and adaptive (self-help) skills--result in an increased need for high quality early intervention services (NECTAC, 2011). According to the Center for Disease Control and Prevention (CDC), at the time of this writing, the prevalence of autism spectrum disorder (ASD) is 1 in 88 children, an increase of $289.5 \%$ since 2000 (Boyle et al., 2011; CDC, 2012). In addition to an increased prevalence of ASD over the past 12 years, the prevalence of learning disabilities increased $17.1 \%$; the prevalence of Attention Deficit Hyperactivity Disorder (ADHD) increased 33.0\%; and the prevalence of hearing loss increased 33.9\% (Boyle et al., 2011). Cerebral Palsy, the most common motor disability in children (CDC, 2011), is on the rise as a result of increased multiple births and survival of preterm infants $(\mathrm{NIH}, 2009)$. Improved screening procedures, such as early detection of hearing loss via newborn hearing screening, have resulted in children being identified as having a delay or disability at earlier ages. For example, in states where newborn hearing screening programs have been effectively implemented, the average age at which children who have a hearing loss are identified has been reduced from about 30 months to 2-3 months of age (Vohr, et al., 1998; Liu, et al., 2008). As a result, there is a greater demand for early intervention services.

\section{PERSONNEL SHORTAGES IN EARLY INTERVENTION (IDEA PART C) SERVICES}

This increase in demand is evident in the annual reports to the Office of Special Education Programs that are filed annually by states and jurisdictions. For many states and jurisdictions, performance on requisite federal indicators is negatively impacted by a significant shortage of early intervention professionals. Highlighting the challenges associated with personnel shortages, the 2012 State Performance Plan (SPP)/Annual Performance Report (APR) for Federal Fiscal Year 2010-2011 (NECTAC, 2012c) stated:

The most frequently cited reason for slippage in providing services in a timely manner continued to be personnel shortages. Staff turnover and a lack of qualified professionals, particularly in rural areas, were cited as major issues in all areas of the country. A few states also reported having an insufficient number of staff to serve the growing number of children being referred and made eligible for early intervention services and an inability to add to their staff due to hiring freezes or the state fiscal climate. (p. 6)

\section{DISCREPANCY IN SERVICE NEED VERSUS ACTUAL} SERVICE PROVISION

In spite of increased demand, research ironically indicates that there are many more children eligible for IDEA Part $\mathrm{C}$ services than who are receiving services. Rosenberg and colleagues (2008) determined that as many as $13 \%$ of children birth through two years have a developmental delay that would qualify them to participate in early intervention services; however, only $2.82 \%$ of the population actually participated in early intervention services in Federal Fiscal Year (FFY) 2011/ Child Count Year 2010 (NECTAC, 2011; NECTAC, 2012b).

\section{EVIDENCE SUPPORTING A TELEHEALTH SERVICE DELIVERY MODEL IN EARLY INTERVENTION PROGRAMS}

Telehealth - the delivery of services via distance technologies - holds promise in addressing the issues of early intervention supply and demand. Several studies demonstrate positive benefits of using a telehealth service delivery model within early intervention programs. Heimerl and Rasch (2009) delivered 224 therapeutic sessions (e.g., occupational therapy, physical therapy, speech-language pathology, and psychology) via a telehealth service delivery model to children birth through two years of age participating in early intervention programs. The researchers concluded that services provided using telehealth technologies are a viable alternative when in-person services are not feasible. Kelso, Fiechtl, Olsen, and Rule (2009) provided multidisciplinary services (e.g., occupational therapy, physical therapy, speech-language therapy) using telehealth technologies and demonstrated savings of time and resources associated with the delivery model. Numerous early intervention programs which serve infants and toddlers with hearing loss are using telehealth to provide the intensity of services needed to foster optimal communication development. Results to date demonstrate high family satisfaction with this method (Behl \& Houston, 2011). Similarly, Cason (2009) reported cost-savings and a high level of parent satisfaction associated with the use of a telehealth service delivery model to provide El occupational therapy services. Later, Cason (2011) aligned potential benefits of a telehealth service delivery model with OSEP performance indicators to demonstrate the positive impact that adoption of the service delivery model would have for states struggling to overcome personnel shortages and increasing demands for El services.

Other studies support the use of a telehealth service delivery model with children, although not specific to the early intervention (birth through two years of age) population. Harper (2006) demonstrated the efficacy of using a telehealth service delivery model for initial 
screening evaluations, follow-up evaluations, and specialized interdisciplinary care for rural families. Results indicated that parents viewed the evaluations provided remotely as being as effective as onsite evaluations. A sub-group of parents who received both onsite and remote services reported high satisfaction with both delivery models and reported no significant differences in their ratings of the evaluation experience.

Baharav and Reiser (2010) compared traditional inperson interventions (i.e., speech therapy twice per week in a clinic setting) to speech therapy interventions provided weekly in a clinic setting, followed by a remote session whereby the clinician coached the parent and provided real-time feedback via videoconferencing. The researchers concluded that the children's skills improved with both service delivery models, and parents perceived the sessions provided via telehealth to be as valuable as those provided directly by the clinician.

Acceptance of a telehealth service delivery model is particularly evident in the field of speech-language pathology. The American Speech-Language-Hearing Association (ASHA) has a "telepractice" special interest group that fosters the provision of high-quality services using telehealth technologies. Other rehabilitation professional associations and regulatory organizations have also created telehealth resources for practitioners and stakeholders (e.g., legislators, reimbursement entities, licensure board members) due to increased interest and informational needs. The American Telemedicine Association's Telerehabilitation Special Interest Group convened an inter-disciplinary licensure portability working group in August, 2010. Through this working group, regular discussions have occurred between representatives of the American Occupational Therapy Association (AOTA), National Board for Certification in Occupational Therapy (NBCOT), American SpeechLanguage-Hearing Association (ASHA), National Council of State Boards of Examiners for Speech-Language Pathology and Audiology (NCSB), American Physical Therapy Association (APTA), and Federation of State Boards of Physical Therapy (FSBPT).

\section{MEASURING THE USE OF TELEHEALTH} WITHIN EARLY INTERVENTION (IDEA PART C) PROGRAMS

Given the growth in the use of telehealth for therapeutic purposes and its potential role in meeting Part $C$ early intervention demands, a study was undertaken to gauge its prevalence and to ascertain perceived barriers to its use. Anecdotal reports of variations in state regulations reflected discrepancies in the types of providers, the types of services, and sources for reimbursement to cover the provision of El services through telehealth. In an effort to gather objective, national-level data on the prevalence of telehealth, a survey was developed and administered across all states and territories.

\section{METHOD}

A six-item online survey using SurveyGizmo (2012) was created to assess utilization of telehealth within El programs. The survey defined and utilized the term 'tele-intervention' in lieu of 'telehealth' in order to capture the focus of El services provided by a variety of health and non-health professionals (i.e., teachers of the Deaf and Hard of Hearing (DHH), behavior specialists). Expert review established content validity for the survey. The National Early Childhood Technical Assistance Center (NECTAC) provided a survey link between December 2011 - January 2012 to IDEA Part C coordinators on its distribution list. A reminder e-mail was sent two weeks following the initial e-mail to encourage completion of the survey. Descriptive analyses were performed for individual survey items.

\section{RESULTS}

Representatives from 26 states and one jurisdiction responded to the telehealth survey. Of these, $30 \%(n=9)$ indicated that they were either using telehealth as an adjunct service delivery model within their El programs $(n=6)$ or plan to incorporate telehealth within the next 1-2 years $(n=3)$. See Figure 1 .

Figure 1: Percentage of states and jurisdictions reporting utilization of telehealth in El programs

\section{Is your state currently delivering any}

Part C services via Tele-intervention?

Response represents 26 states \& 1 jurisdiction

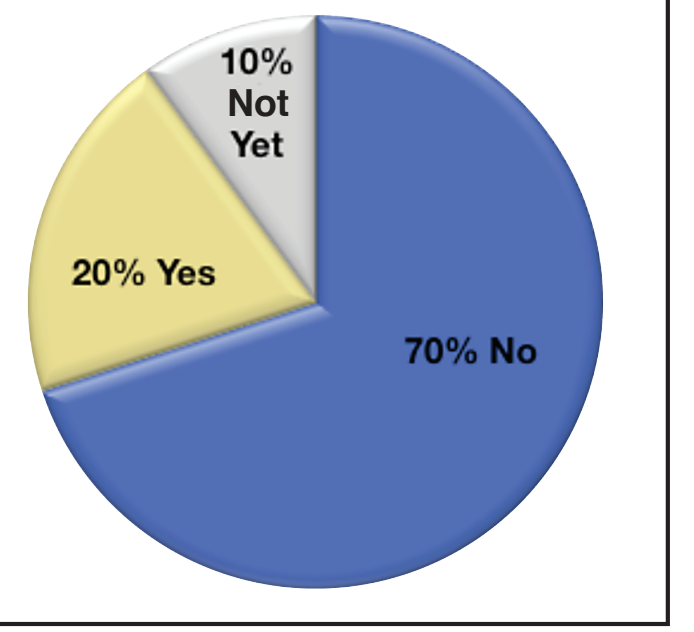




\section{TELEHEALTH EARLY INTERVENTION PROVIDERS}

Respondents were given a list of typical early intervention providers and then asked to identify the types of providers within their state using telehealth to deliver early intervention services. Table 1 summarizes the types of providers reported by the survey respondents.

Three of the six states reporting use of telehealth within their El programs identified speech/language pathologists, and two states identified teachers of the Deaf and Hard of Hearing as well as behavior specialists. Early intervention developmental specialists, occupational therapists, and physical therapists were identified as implementing telehealth by one state each. One respondent identified the use of telehealth for remote participation of providers in Individual Family Service Plan (IFSP) meetings. a varying number of states reporting the use of Part $C$ dollars for all of the identified providers. Medicaid was reported as allowable for allied health specialists, and one state also reported use of Medicaid funding for interpreters. Private insurance was the least reported source of reimbursement.

Table 2: State/jurisdiction frequencies for allowable sources of reimbursement by provider type
Table 1: Frequencies for providers reported as using telehealth within Early Intervention

\begin{tabular}{|l|l|l|}
\hline $\begin{array}{l}\text { Provider type/professional } \\
\text { discipline }(\mathrm{n}=6)\end{array}$ & Count & Percent \% \\
\hline $\begin{array}{l}\text { Early intervention } \\
\text { developmental specialists } \\
\begin{array}{l}\text { Teachers of the Deaf } \\
\text { and Hard of Hearing (DHH) }\end{array}\end{array}$ & 1 & $16.7 \%$ \\
$\begin{array}{l}\text { Speech-language } \\
\text { pathologists } \\
\text { Occupational therapists }\end{array}$ & 1 & $33.3 \%$ \\
\hline $\begin{array}{l}\text { Physical therapists } \\
\text { Behavior specialists }\end{array}$ & 1 & $16.7 \%$ \\
\hline Audiologists & 1 & $16.7 \%$ \\
\hline $\begin{array}{l}\text { Other (describe) - } \\
\text { IFSP meeting participation }\end{array}$ & 1 & $16.7 \%$ \\
\hline
\end{tabular}

\section{REIMBURSEMENT FOR TELEHEALTH WITHIN EARLY INTERVENTION}

Respondents were asked to identify the reimbursement sources for El services provided using a telehealth service delivery model, specifically Part $\mathrm{C}$ dollars, state Medicaid, and private insurance. Table 2 summarizes the number of states reporting the allowable sources of reimbursement by provider type. Part $\mathrm{C}$ dollars were the most frequently cited allowable source for reimbursement identified, with

\section{BARRIERS TO TELEHEALTH IMPLEMENTATION}

Expressed barriers and concerns for the implementation of telehealth as a delivery model within Part C programming included security issues $(40 \% ; n=11)$; privacy issues $(44 \% ; n=12)$; concerns about quality of services delivered via telehealth $(40 \% ; n=11)$; and lack of evidence to support the effectiveness of a telehealth service delivery model within IDEA Part $C$ programming $(3 \% ; n=1)$. Reimbursement policy and billing processes and technology infrastructure were also identified as barriers impacting the implementation of telehealth programming. See Table 3. 
Table 3: Expressed barriers and concerns associated with a telehealth service delivery model

If your state does not currently provide payment

for services provided through tele-intervention,

what are the barriers or concerns about this model

of service delivery? (Check all that apply)

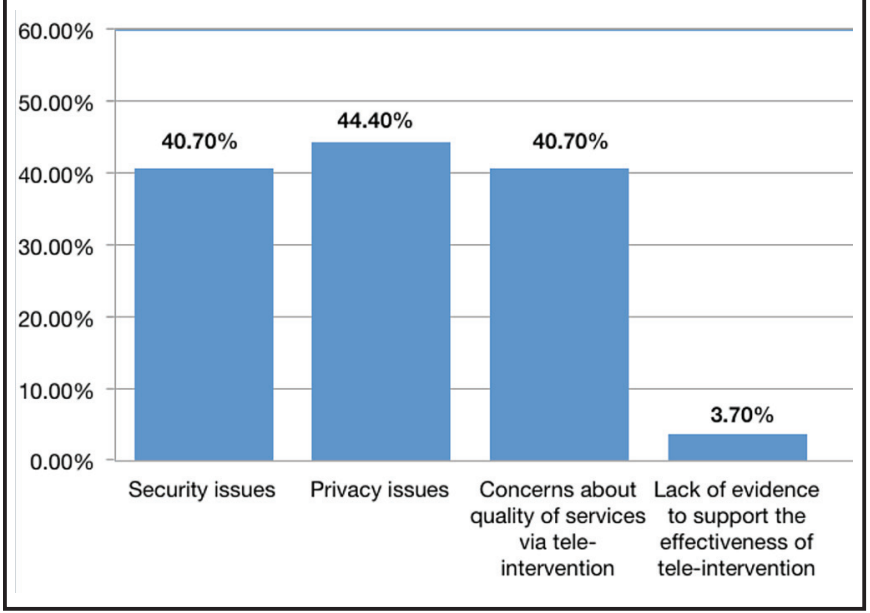

\section{DISCUSSION}

Provider shortages impact the quantity and quality of services available for children with disabilities and developmental delay, particularly in rural areas. The results of this survey demonstrate that states and jurisdictions are beginning to explore and implement the use of telehealth within their IDEA Part C programs, which will help in addressing these shortages. Although only six of the respondents reported that they are implementing telehealth in their state, anecdotal evidence through professional networking reveals that there are at least seven additional states that are implementing a telehealth service delivery model but who did not respond to the survey. This adjusts the number of states and jurisdictions to a minimum of 13 states incorporating telehealth technologies within their El programming.

While many states are utilizing telehealth within their Early Intervention (IDEA Part C) services in order to improve access and overcome personnel shortages, barriers persist. Policy development, education of stakeholders, research, utilization of secure and private delivery platforms, and advocacy may facilitate more widespread adoption of telehealth within IDEA Part C programs across the country.

A telehealth service delivery model can improve access to services for families of children who qualify for El services, which in turn will be reflected in improved performance by states and jurisdictions on OSEP indicators. Timely receipt of services, setting of service delivery (i.e., natural environment), child and family outcomes, early identification of eligible infants and toddlers, initiation of services within a 45-day timeline, and transition planning may all be facilitated through the use of a telehealth service delivery model (Cason, 2011). Telehealth creates access to specialists and disciplines not available within local communities, thereby facilitating the receipt of timely services. Remote providers can connect with children and families within their natural environments. Additionally, a telehealth service delivery model can be used to: 1) provide early intervention services with children and caregivers; 2) connect caregivers and on-site providers with remote providers for consultation and collaboration; 3) facilitate IFSP team collaboration through remote participation in team meetings; and 4) provide interpretive services. 


\section{CONCLUSION}

Increased demand for quality early intervention services coupled with provider shortages impact the quantity and quality of services available for children with disabilities and developmental delay, particularly in rural areas. Developmental specialists, teachers of the Deaf and Hard of Hearing $(\mathrm{DHH})$, speech-language pathologists, occupational therapists, physical therapists, behavior specialists, audiologists, and interpreters are using telehealth within IDEA Part C programs to deliver habilitation services and specialty consultations. While many states are incorporating telehealth within their Early Intervention (IDEA Part C) programs in order to improve access and overcome personnel shortages, barriers persist. There is a need to develop policy, educate stakeholders, utilize secure and private telehealth delivery platforms, engage in advocacy, and conduct research on the use of telehealth in IDEA Part C programs. Directions for future research include outcomes research on the efficacy of telehealth as a delivery model for El services, psychometric studies to examine the reliability and validity of remote administration of commonly utilized $\mathrm{El}$ assessment tools, cost-benefit analyses, and research examining reimbursement for El services provided via telehealth.

\section{KEY POINTS}

- Many states are incorporating telehealth within their Early Intervention/Individuals with Disabilities Education Improvement Act (IDEA) Part C programs to improve access to services and overcome personnel shortages.

- Developmental specialists, teachers of the Deaf and Hard of Hearing (DHH), speech-language pathologists, occupational therapists, physical therapists, behavior specialists, audiologists, and interpreters are using telehealth within IDEA Part C programs to deliver habilitation services and specialty consultations.

- Policy development, education of stakeholders, research, utilization of secure and private delivery platforms, and advocacy are important strategies to support widespread adoption of telehealth as a service delivery model within IDEA Part C programs. 


\section{REFERENCES}

1. Baharav, E. \& Reiser, C. (2010). Using telepractice in parent training in early autism. Telemedicine and e-Health, 16, 727-731.

2. Behl, D., Houston, K. T, Guthrie, W. S., \& Guthrie, N. (2010). Tele-intervention: The wave of the future fits families' lives today. Exceptional Parent, 40, 23-28.

3. Boyle, C., Boulet, S., Scheve, L., Cohen, R., Blumber, S., Yeargin-Allsopp, M...Kogan, M. (2011). Trends in the prevalence of developmental disabilities in US children, 1997-2008. Pediatrics, 127, 1034-1043. doi: 10:10.1542/peds.2010-2989. Available at: http:// pediatrics.aappublications.org/content/early/2011/05/19/ peds.2010-2989.full.pdf+html

4. Cason, J. (2009). A pilot telerehabilitation program: Delivering early intervention services to rural families. International Journal of Telerehabilitation, 1, 29-37.

5. Cason, J. (2011). Telerehabilitation: An adjunct service delivery model for early intervention services. International Journal of Telerehabilitation, 3(1), 19-30. doi: 10.5195/IJT.2011.6071

6. Center for Disease Control and Prevention [CDC]. (2011). Cerebral Palsy occurrence in the US. Retrieved from http://www.cdc.gov/features/dscerebralpalsy/index.html

7. Center for Disease Control and Prevention [CDC]. (2012). Autism Spectrum Disorders: Data and statistics. Retrieved from http://www.cdc.gov/NCBDDD/autism/ data.html

8. Heimerl, S., \& Rasch, N. (2009). Delivering developmental occupational therapy consultation services through telehealth. Developmental Disabilities Special Interest Section Quarterly, 32(3), 1-4.

9. Individuals with Disabilities Education Improvement Act [IDEA] of 2004, 20 U.S.C 1400 et seq. (2004).

10. Kelso, G., Fiechtl, B., Olsen, S., \& Rule, S. (2009). The feasibility of virtual home visits to provide early intervention: A pilot study. Infants \& Young Children, 22, 332-340.

11. Liu, C.L., Farrell, J., MacNeil, J.R., Stone, S., \& Barfield, W. (2008). Evaluating loss to follow-up in newborn hearing screening in Massachusetts. Pediatrics, 121, e335-e343.

12. National Early Childhood Technical Assistance Center [NECTAC]. (2011). The importance of early intervention for infants and toddlers with disabilities and their families. Retrieved from http://www.nectac.org/ pdfs/ pubs/importanceofearlyintervention.pdf

13. National Early Childhood Technical Assistance Center [NECTAC]. (2012a). Early intervention program for infants and toddlers with disabilities (IDEA Part C). Retrieved from http://www.nectac.org/partc/partc.asp

14. National Early Childhood Technical Assistance Center [NECTAC]. (2012b). Annual appropriations and number of children served under Part C of IDEA: Federal fiscal years 1987-2012. Retrieved from http://www.nectac.org/ partc/partcdata.asp

15. National Early Childhood Technical Assistance Center [NECTAC]. (2012c). Part C SPP/APR indicator analyses: 2012 SPP/APR indicator analyses FFY 2010-2011. Retrieved from http://www.nectac.org/partc/partcapr. asp
16. National Institute of Health. (2009, December). Cerebral palsy: Hope through research. National Institute of Neurological Disorders and Stroke. NIH Publication No. 10-159. Retrieved from http://www.ninds.nih.gov/ disorders/cerebral_palsy/detail_cerebral_palsy.htm

17. Rosenberg, S., Zhang, D. \& Robinson, C. (2008). Prevalence of developmental delays and participation in early intervention services for young children. Pediatrics, 121, e1503-e1509. doi: 10.1542/peds.20071680.

18. SurveyGizmo [Computer software]. (2012). Boulder, Colorado: SurveyGizmo.

19. Vohr, B.R., Carty, L.M., Moore, P.E., \& Letourneau, K. (1998). The Rhode Island Hearing Assessment Program: Experience with statewide hearing screening (19931996). Journal of Pediatrics, 133, 353-357. 
